\title{
Evolution of microstructure and properties in laser cladding of a Ni-Cr-B-Si hardfacing alloy
}

\author{
I. Hemmati, V. Ocelík \& J. Th. M. De Hosson \\ Materials Innovation Institute M2i, Department of Applied Physics, \\ University of Groningen, The Netherlands
}

\begin{abstract}
Ni-Cr-B-Si coatings are used in many industrial applications in order to improve wear and/or corrosion properties. These coatings have traditionally been deposited by thermal spray techniques but the laser cladding process is also being increasingly employed to produce Ni-Cr-B-Si coatings with superior functional properties. In this research, the microstructural evolutions and the phase formations in the laser cladding of a Ni-Cr-B-Si alloy and their effects on the hardness of the clad layer are discussed. Results of this study show various types of boride and carbide phases can form in each track of the clad layer. These changes demonstrate the potential for tuning the properties of these coating by controlling the processing conditions.
\end{abstract}

Keywords: $\mathrm{Ni}-\mathrm{Cr}-\mathrm{B}-\mathrm{Si}$, laser cladding, microstructural evolution.

\section{Introduction}

Significant development of high power lasers has encouraged the commercial application of laser-assisted surface modification technologies. Laser cladding is one of these technologies in which an alloy powder of a desired composition and a thin layer of a substrate material are melted under laser irradiation and then rapidly solidified to form a dense coating with minimum dilution and metallurgical bond to the base material The rapid solidification associated with laser cladding is able to generate novel microstructures with extended solubilities, metastable phases and refined features [1-3].

The Ni-Cr-B-Si alloys are boride-containing Nickel base hardfacing alloys with excellent wear and corrosion resistance in chemically-aggressive environments and high temperature working conditions [4-6]. These alloys have traditionally been 
deposited by thermal spray techniques but the laser cladding process is also being increasing employed to produce dense and metallurgically-bonded coatings with superior functional properties [7, 9]. The phase transformations and microstructures of laser deposited $\mathrm{Ni}-\mathrm{Cr}-\mathrm{B}-\mathrm{Si}$ coatings have been studied by various researchers [10-14]. Although the chemical composition of the clad materials used by these researchers are mostly identical (usually Colmonoy 5 or Colmonoy 6 from Wall Colmonoy Ltd. or equivalent compositions from other companies) and the clad layers are deposited with similar laser cladding velocities $(5-15 \mathrm{~mm} / \mathrm{s})$ on steel substrates, the reported microstructures of the clad layers vary significantly and include a broad range of phases from blocky [11,14], butterflyshape [12] or floret-shape [14] borides to rod-like [12] or dendritic carbides [11, 14] and various combinations of these phases along with $\mathrm{Ni}-\mathrm{Ni}_{3} \mathrm{~B}$ or $\mathrm{Ni}-\mathrm{Ni}_{3} \mathrm{Si}$ eutectics in the interdendritic regions $[7,15]$. The unreliability of identifying the reflections of the X-ray Diffraction (XRD) patterns obtained from Ni-Cr-B-Si laser deposited coatings which is caused by peak overlaps and lattice distortions because of extended solubility and stresses in the clad layer, makes the phase analysis even more complicated [15].

In the present work, a Ni-Cr-B-Si alloy is deposited by laser cladding with powder injection and a detailed microstructural analysis is performed on the clad layers to study the microstructural evolution in this important group of hardfacing alloys. In addition, the hardness values of various microstructures are measured and finally the microstructural evolution and its implications for properties of the coating are discussed.

\section{Experimental procedure}

Colmonoy 69 powder from Wall Colmonoy Ltd. was deposited on S355 steel rods with $50 \mathrm{~mm}$ diameter using a continuous wave IPG fiber laser with wavelength of $1.07 \mu \mathrm{m}$. A defocused laser beam was applied with a laser spot size of around $3.5 \mathrm{~mm}$ on the substrate surface. Chemical composition of the cladding and substrate materials are presented in Table 1. Powder feeding system consisted of Metco Twin 10C powder feeder, argon as carrier and shielding gas and ALOtec Dresden $\mathrm{GmbH} \mathrm{Cu}$-based side cladding nozzle with the cyclone and $2 \mathrm{~mm}$ nozzle opening. Single layer samples with a thickness of 0.9-1.1 mm each consisted of 5 tracks with one 33\% overlapping were deposited at scanning speed of $5 \mathrm{~mm} / \mathrm{s}$ with a laser power of $900 \mathrm{~W}$. Dilution from the substrate calculated by dividing the surface area of the deposited layer to the total area of the deposited layer plus remelted substrate was around 10 percent. The Ni-Cr-BSi coatings are very susceptible to cracking as a result of their low toughness and a big difference in the Coefficient of Thermal Expansion (CTE) between the

Table 1: Nominal chemical composition of substrate and clad materials (wt.\%).

\begin{tabular}{|c|c|c|c|c|c|c|c|c|c|}
\hline Material & Ni & Fe & Cr & Si & C & B & Mn & Mo & Cu \\
\hline Colmonoy 69 & Bal. & 3 & 16.5 & 4.8 & 0.55 & 3.6 & - & 3.5 & 2.1 \\
\hline S355 & 0.7 & Bal. & 0.2 & 0.55 & 0.12 & - & 1.65 & 0.08 & 0.3 \\
\hline
\end{tabular}


steel substrate and the Ni-base coating [16-18]. Reducing the cooling rate of the deposits is a widely used method to reduce the cracking tendency of these materials $[16,18]$. In the present work, the substrate was preheated to $500^{\circ} \mathrm{C}$ immediately before cladding using a tube furnace and the coated bars were left in the furnace to cool slowly down to the room temperature after their cladding.

Sample from the transversal and longitudinal cross sections were cut and prepared by standard mechanical grinding and polishing. A Philips XL30 FEG

Scanning Electron Microscope (SEM) equipped with Energy Dispersive Spectroscopy (EDS) and Electron Backscatter Diffraction (EBSD) was used to perform detailed microstructural analysis and phase characterization. To study the microstructural evolution in the clad layer, various locations in each track were studied on polished samples and after etching with the solution consisting of $7 \mathrm{ml} \mathrm{HF}, 3 \mathrm{ml} \mathrm{HNO}_{3}$ and $5 \mathrm{ml} \mathrm{H}_{2} \mathrm{O}$. Vickers microhardness was measured by a CSM Revetest machine at an applied load of $4.9 \mathrm{~N}$. Three rows of indentation with a distance of $100 \mu \mathrm{m}$ from one other were made on a number of tracks and the average for each track was calculated.

\section{Results and discussion}

\subsection{Microstructure of different tracks}

To analyze the microstructural evolution, the microstructure of the clad layer was studied at various locations in each track. As mentioned before, the high hardness and wear resistance of the $\mathrm{Ni}-\mathrm{Cr}-\mathrm{B}-\mathrm{Si}$ alloys are produced by various kinds of $\mathrm{Cr}$ borides and carbides and $\mathrm{Ni}$ borides. Because of the low atomic number of $\mathrm{B}$ and $\mathrm{C}$, borides and carbides can be easily observed with the Backscattered Electron (BSE) detector in SEM. Consequently, the observation of boride and carbide phases was done on the polished sample using the BSE detector in SEM.

Figure 1 shows the dominant microstructures observed in tracks 1 to 5 in which huge differences in size, shape and even type of the precipitates can be easily noticed. In track 1 and 2 , the precipitates were mostly cuboids and irregular in shape. The only difference between the precipitates in these two tracks was the bigger sizes of precipitates in track 2 . In track 3 , the butterflyshape precipitates were the dominant ones but there were slight amounts of blocky precipitates (similar to track 2) and a number of dendritic shape precipitates. In tracks 4 and 5, the microstructure was entirely changed and consisted of a mixture of floret-shape and dendritic phases. For the sake of simplicity, the microstructures of tracks 2, 3 and 4 (and 5) will be called microstructures No. 1, No. 2 and No. 3 respectively. Figure 1 shows that in spite of the constant chemistry and cladding parameters, it is possible to obtain different types of microstructures in laser deposition of the alloy under investigation. Apart from the possibility of microstructural changes from one track to the next one, it was observed that these microstructural changes can sometimes happen even in one track from bottom to the top of the track. Also, abrupt changes of microstructure between tracks were observed. These last two 
observations are shown in Figure 2. Figure 2-a shows the cross section of track 5 in which after a thin layer of cellular dendritic growth adjacent to the substrateclad interface (which was present in all tracks), first cuboidal and then butterflyshape precipitates are formed and finally the mixture of floret-shape and dendritic precipitates becomes dominant and covers the majority of clad microstructure. Figure 2-b is an indication that there are some sharp thresholds at which the phase changes can happen suddenly.
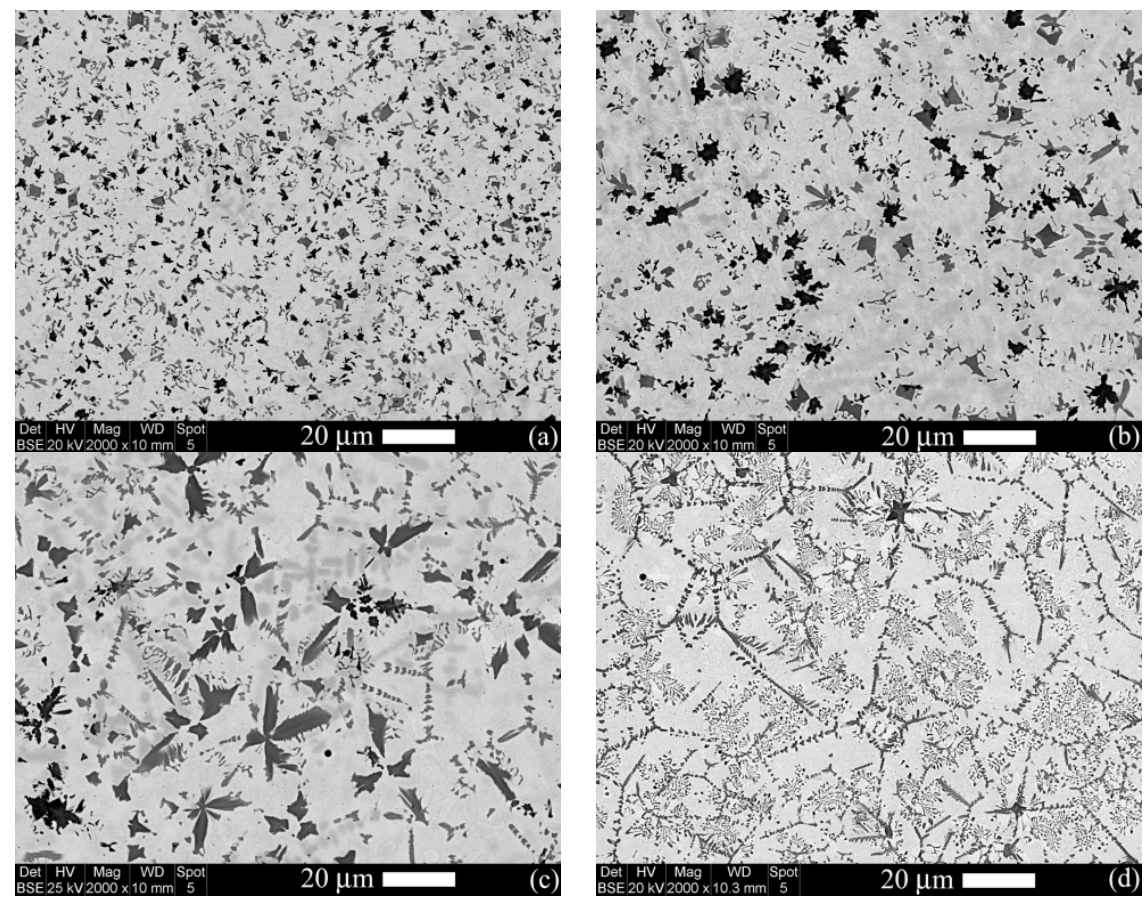

Figure 1: $\quad$ Microstructure of (a) track 1, (b) track 2, (c) track 3 and (d) tracks 4 and 5 .
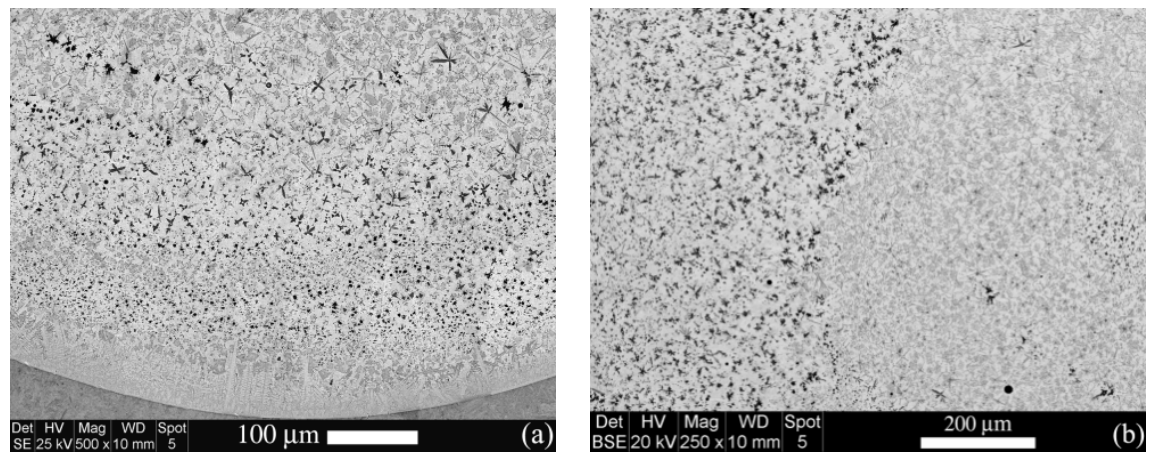

Figure 2: (a) Microstructural change from the bottom to the top of track 5, (b) abrupt change of microstructure between tracks 3 and 4 . 


\subsection{Characterization of the precipitates and the matrix}

EDS and EBSD were employed to identify the type of various phases. EDS line scanning determined the elements present in each phase and at the next step, EBSD identified the type and grain structure of the phase. As explained in the previous section, four major types of precipitates were observed, irregular cuboids, butterfly/wing-shape, dendritic and floret-shape. EDS and EBSD scans showed that the irregular cuboids were polycrystalline $\mathrm{CrB}$ (Figure 3), the butterfly and wing-shape ones were single-crystalline $\mathrm{Cr}_{5} \mathrm{~B}_{3}$ (Figure 4) and the dendritic ones were single-crystalline $\mathrm{Cr}_{7} \mathrm{C}_{3}$ (Figure 5).


Figure 3: (a) SEM image $\left(70^{\circ}\right.$ tilted) and (b) the inverse pole figure (IPF) map of irregular cuboid of $\mathrm{CrB}$.
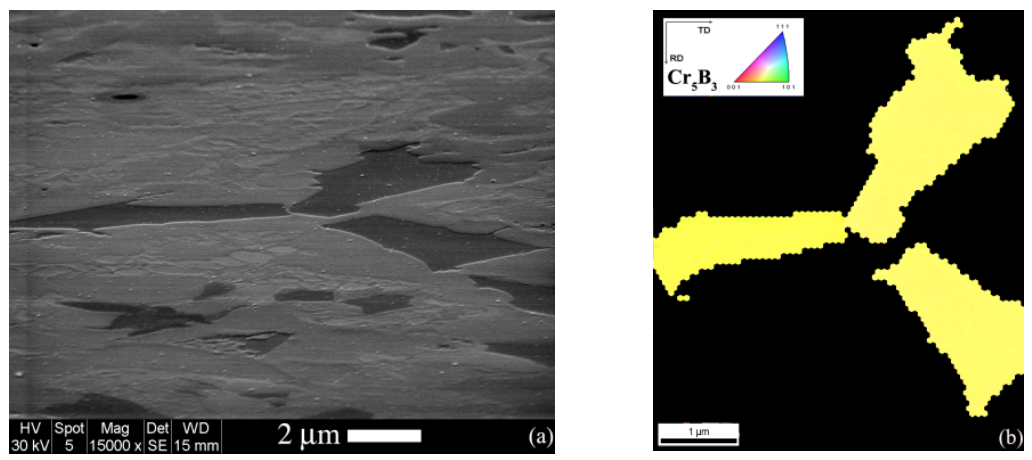

Figure 4: (a) SEM image ( $70^{\circ}$ tilted) and (b) the inverse pole figure (IPF) map of the wing-shape $\mathrm{Cr}_{5} \mathrm{~B}_{3}$.

According to the Cr-B phase diagram [19], three types of $\mathrm{Cr}$ borides can form on the Cr-rich side of the diagram: $\mathrm{CrB}, \mathrm{Cr}_{5} \mathrm{~B}_{3}$ and $\mathrm{Cr}_{2} \mathrm{~B} . \mathrm{CrB}$ forms directly from the melt and $\mathrm{Cr}_{5} \mathrm{~B}_{3}$ may form either directly from the melt or by the peritectic reaction of $\mathrm{CrB}$ and the melt. The floret-shape structure was difficult to characterize by EBSD because of its very fine scale but the EDS line scanning showed that this structure consisted of alternating layers of $\mathrm{Cr}$ boride and $\mathrm{Ni}$ 

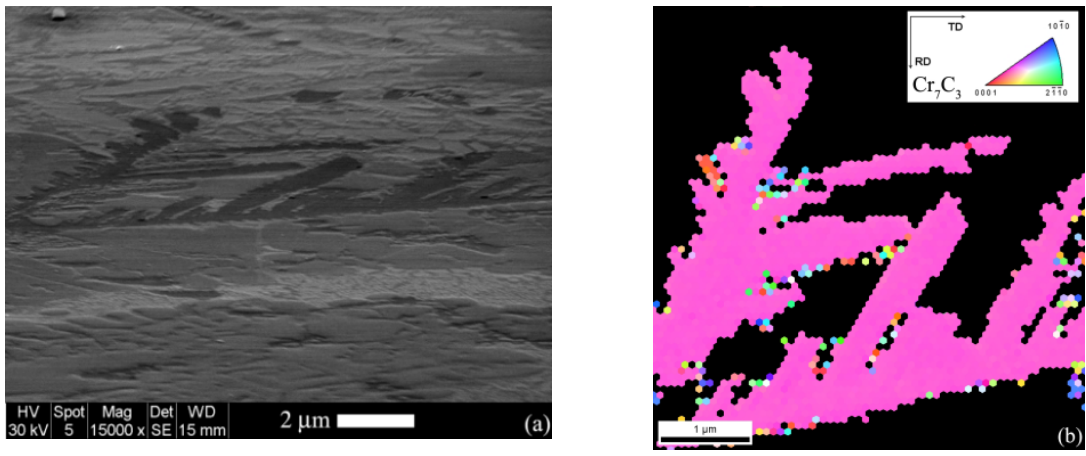

Figure 5: (a) SEM image $\left(70^{\circ}\right.$ tilted) and (b) the inverse pole figure (IPF) map of the dendritic $\mathrm{Cr}_{7} \mathrm{C}_{3}$.

(Figure 6). Campbell and Kattner [19] extrapolated the Cr-B binary phase diagram to $\mathrm{Ni}-\mathrm{Cr}-\mathrm{B}$ ternary system and predicted that the following invariant transformation may occur at $1222^{\circ} \mathrm{C}$ :

$$
L \rightarrow \mathrm{Cr}_{2} \mathrm{~B}+\alpha(\mathrm{Cr})+\gamma(\mathrm{Ni})
$$

$\alpha(\mathrm{Cr})$ may occur along with the $\mathrm{Cr}_{2} \mathrm{~B}$ and it seems reasonable to assume the floret-shape structure as a eutectic mainly consisting of $\mathrm{Ni}$ and $\mathrm{Cr}_{2} \mathrm{~B}$ [20].

Analysis of the matrix (the continuous white background in Figures 1 and 2) showed that islands of $\mathrm{Ni}$ (detected by EDS and EBSD) were surrounded by a eutectic structure. Small additions of $\mathrm{B}$ and $\mathrm{Si}$ to Ni lower the melting point of $\mathrm{Ni}$ by forming $\mathrm{Ni}-\mathrm{Ni}_{3} \mathrm{Si}$ at $1152^{\circ} \mathrm{C}$ and $\mathrm{Ni}-\mathrm{Ni}_{3} \mathrm{~B}$ eutectic at $1093^{\circ} \mathrm{C}[15,21]$. Depending on the ratio of $\mathrm{Si}$ to $\mathrm{B}$, either $\mathrm{Ni}-\mathrm{Ni}_{3} \mathrm{~B}$ or $\mathrm{Ni}-\mathrm{Ni}_{3} \mathrm{Si}$ eutectic may be the dominant eutectic reaction. In the case of Colmonoy 69 alloy, $\mathrm{Ni}-\mathrm{Ni}_{3} \mathrm{~B}$ will be the main eutectic structure because the $\mathrm{Si} / \mathrm{B}$ ratio is much lower than $3[21,22]$. This has been confirmed for similar alloys in which depending on the local composition, the $\mathrm{Ni}-\mathrm{Ni}_{3} \mathrm{~B}$ stable solidification or the $\mathrm{Ni}-\mathrm{Ni}_{2} \mathrm{~B}$ metastable solidification may happen because of the non-equilibrium rapid solidification involved in the laser cladding [15].
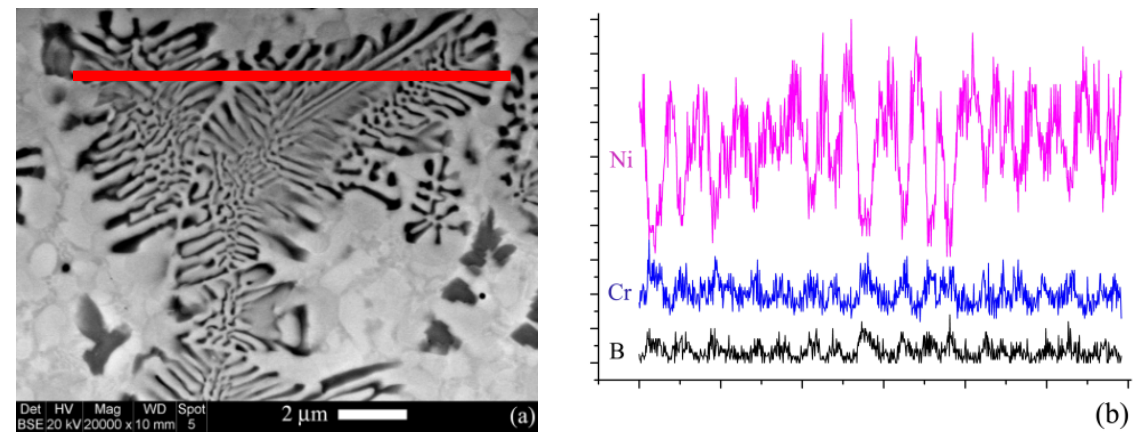

(b)

Figure 6: (a) SEM image of the floret-shape structure (b) result of the EDS line scan along the red line in (a) showing the variations of $\mathrm{Ni}, \mathrm{Cr}$ and $\mathrm{B}$. 


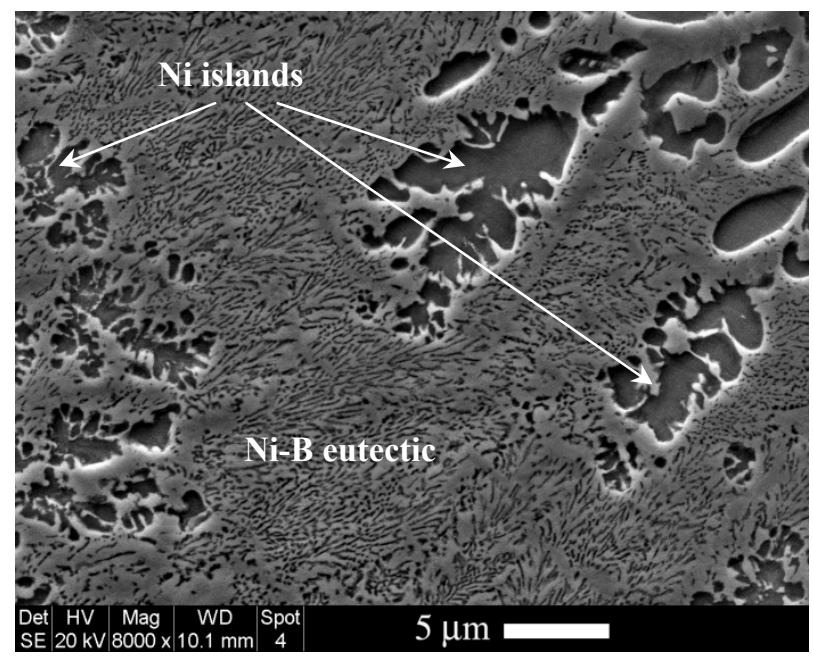

Figure 7: $\quad$ Microstructure of the matrix with Ni islands and Ni-B eutectic.

\subsection{The mechanisms of microstructural evolution}

The microstructural evolution during the solidification stage depends on the relative nucleation and growth kinetics of the competing structures [23]. The observed phase changes in different tracks of the Ni-Cr-B-Si deposit show that a series of phase selection processes are happening during the solidification stage.

The phase selection phenomena can be nucleation-controlled, growthcontrolled or both. When the interface attachment kinetics of the competing phases are comparable, then the competitive nucleation principles apply but if there is a significant difference of two or three orders of magnitude in the interface growth kinetics, the phase selection process will be growth-controlled [24]. In the nucleation-controlled regime, the competition is largely determined by the relative magnitudes of $\Delta G^{*}$, i.e. the energy barrier to nucleation. $\Delta G^{*}$ itself is proportional to $\sigma_{l s}^{3} /\left(\Delta G_{V}\right)^{2}$ in which $\sigma_{l s}^{3}$ is the solid-liquid interface energy and $\Delta G_{V}$ is the free energy change associated with the formation of each solid phase [23]. For the undercooling $\Delta T, \Delta G_{V}$ is given by the following equation [25]:

$\Delta G_{V}=L_{V} \Delta T / T_{m}$ where $L_{V}$ is the latent heat of fusion per unit volume and $T_{m}$ is the melting temperature of the phase. The above equations show that many parameters can play a role in determining which phase nucleates more easily. There is little information about the solid-liquid interface energies in this alloy system but the standard free energy of formation for some of the involved phases is known. For example, formation of $\mathrm{Cr}_{7} \mathrm{C}_{3}$ releases more than twice as much energy as formation of $\mathrm{CrB}$ [26]. There is not enough thermodynamic data to fully compare the formation of various borides and carbides observed in the alloy system under investigation but based on the microstructural evolutions and possibility of sudden changes in phase constituents, it seems reasonable to 
assume the existence of substantial differences between the properties of the observed phases such as their interfacial energy or free energy of formation.

In the current work, a constant cladding speed was used which means that the solid/liquid interface growth rate will be constant in any specific depth of the melt pool and hence, the phase selection process is nucleation-controlled. On the other hand, the same changes in the phase formation from the bottom to the top of the fifth track (as shown in Figure 2(a)) suggest that the growth rate may also play a role because in laser cladding, the solid/liquid interface growth rate increases from bottom to the top of the melt pool [27].

The heat accumulation in the cladding process will reduce both the temperature gradient in the melt and the cooling rate [20]. This means that both nucleation and growth conditions can change during the cladding process. If the alloy composition has the potential to follow various phase formations paths, different phase selection phenomena can occur as observed in the Colmony 69 laser deposited coatings. Further analysis and experiments are necessary to clarify the exact mechanisms of phase selection and microstructural evolution during laser cladding of Ni-Cr-B-Si hardfacing alloys.

\subsection{Hardness of various microstructures}

By measuring the hardness values in each track, it was possible to partly evaluate the effect of microstructural evolutions on the mechanical properties of the coatings. Figure 8(a) shows the hardness graphs for the three observed microstructures. Microstructure No. 1 and No. 3 has the lowest and the highest hardness values with an average of around 750 and $900 \mathrm{HV}_{0.5}$ respectively and the microstructure No. 2 falls between these two. These hardness differences can be explained by the fact that the hardness of a deposit consisting of hard particles and matrix is controlled not only by the amount of $\mathrm{Cr}$ rich hard particles, but also by the volume fraction of the eutectic phases present in the matrix [28]. In the case of Ni-Cr-B-Si alloys, these eutectic phases (mainly $\mathrm{Ni}_{3} \mathrm{~B}$ and $\mathrm{Ni}_{3} \mathrm{Si}$ ) are also very hard and can significantly contribute to the overall hardness of the deposit. In the present work, the hardness of the eutectic structure was measured to be more than $1000 \mathrm{HV}_{0.5}$. Figure 8-b shows one of these measurements in which an indentation is made on an area entirely covered with the eutectic structure with some $\mathrm{Ni}$ islands and without any boride particles. The hardness of this indentation was $1073 \mathrm{HV}_{0.5}$ which is significantly higher than the maximum average hardness of the deposit. This shows the important role of the eutectic structures in obtaining high levels of hardness in this family of alloys. As all $\mathrm{Cr}$ boride and carbide particles have high hardness values (1000 to $2000 \mathrm{HV}$ ) [28], it seems that the main reason for the differences in hardness values of the observed microstructure is in the amount of the eutectic structure present in their matrix. This is because of fact that the formation of $\mathrm{CrB}(17.2 \mathrm{wt} \% \mathrm{~B}), \mathrm{Cr}_{5} \mathrm{~B}_{3}$ (11.1 wt.\% B) or $\mathrm{Cr}_{2} \mathrm{~B}(9 . .4$ wt.\% B) [29] at higher temperatures will deplete the melt from $\mathrm{B}$ and consequently it will influence the formation of the eutectic structures at lower temperatures. Microstructure No. 3 mostly consists of $\mathrm{Cr}_{2} \mathrm{~B}$ with lower $\mathrm{B}$ content which means that more $\mathrm{B}$ will remain in the melt and 

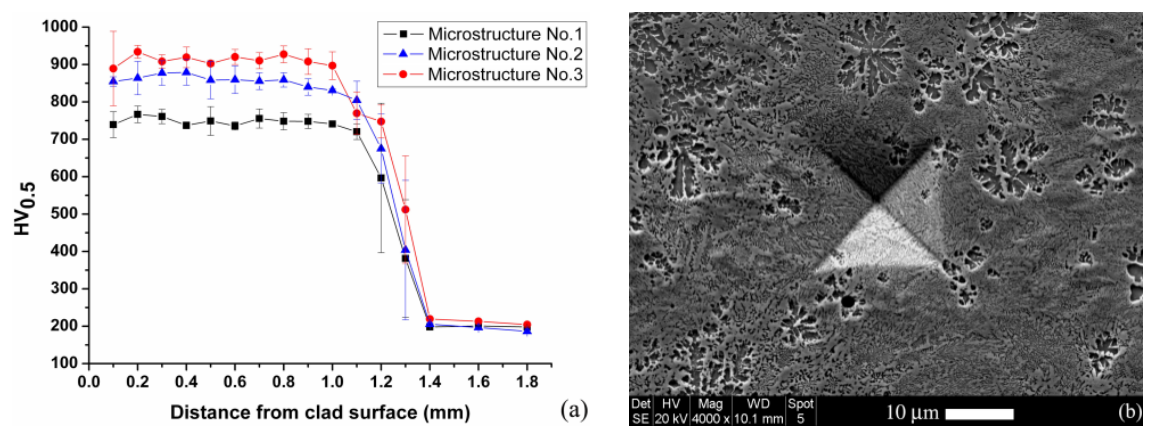

Figure 8: (a) Graph of hardness values for three observed microstructures, (b) an indentation on the Ni-B eutectic structure with a hardness value of $1073 \mathrm{HV}_{0.5}$.

higher percentage of the $\mathrm{Ni}-\mathrm{Ni}_{3} \mathrm{~B}$ eutectic will form at the final stage of solidification.

\section{Conclusions}

In this study, the single layer deposits of a Ni-Cr-B-Si alloy were deposited by laser cladding with powder injection and detailed microstructural and phase analysis were performed in an attempt to clarify the reasons for different reports on the types of phases observed in the Ni-Cr-B-Si laser deposited coatings. The results of this work show the possibility of obtaining various microstructures along the clad layer. The possible mechanisms for the microstructural evolution by phase selection are discussed and the effect of different phase formation paths on the hardness of the clad layer is addressed. These findings demonstrate the potential for tuning the properties of the Ni-Cr-B-Si coatings by controlling the processing conditions.

\section{Acknowledgements}

The work is part of the research program of M2i (Materials innovation institute, The Netherlands) Project number: MC7.06259. The Wall Colmonoy Ltd. (The UK) is acknowledged for providing the cladding powders.

\section{References}

[1] Toyserkani E. Laser Cladding. CRC Press, 2005.

[2] Vilar R. Journal of laser applications 1999;11:64-79.

[3] Steen WM. Journal of optics a: pure and applied optics 2003;5:S3-S7.

[4] Ming Q, Lim LC, Chen ZD. Surface and coatings technology 1998;106:174-182. 
[5] Miguel JM, Guilemany JM, Vizcaino S. Tribology international 2003;36:181-187.

[6] Fernández E, Cadenas M, González R, Navas C, Fernández R, Damborenea JD. Wear 2005;259:870-875.

[7] Conde A, Zubiri F, De Damborenea YJ. Materials science and engineering a 2002;334:233-238.

[8] Serres N, Hlawka F, Costil S, Langlade C, MacHi F. Journal of thermal spray technology 2011;20:336-343.

[9] Planche MP, Liao H, Normand B, Coddet C. Surface and coatings technology 2005;200:2465-2473.

[10] Haemers TAM, Rickerby DG, Lanza F, Geiger F, Mittemeijer EJ. Journal of materials science 2000;35:5691-5698.

[11] Kaul R, Ganesh P, Albert SK, Jaiswal A, Lalla NP, Gupta A, Paul CP, Nath AK. Surface engineering 2003;19:269-273.

[12] Das CR, Albert SK, Bhaduri AK, Sudha C, Terrance ALE. Surface engineering 2005;21:290-296.

[13] Lim LC, Ming Q, Chen ZD. Surface and coatings technology 1998;106:183-192.

[14] Kesavan D, Kamaraj M. Surface and coatings technology 2010;204:40344043.

[15] Li Q, Zhang D, Lei T, Chen C, Chen W. Surface and coatings technology 2001;137:122-135.

[16] Zhang $\mathrm{H}$, Shi Y, Kutsuna M, Xu GJ. Nuclear engineering and design 2010;240:2691-2696.

[17] Wang F, Mao H, Zhang D, Zhao X, Shen Y. Applied surface science 2008;255:3267-3275.

[18] Wang D-s, Liang E-j, Chao M-j, Yuan B. Surface and coatings technology 2008;202:1371-1378.

[19] Campbell CE, Kattner UR. Calphad: computer coupling of phase diagrams and thermochemistry 2002;26:477-490.

[20] Sudha C, Shankar P, Rao RVS, Thirumurugesan R, Vijayalakshmi M, Raj B. Surface and coatings technology 2008;202:2103-2112.

[21] Tanaka K. Hardfacing Ni-base Alloys. U.S. Patent 4,404,049, 1983.

[22] Gurumoorthy K, Kamaraj M, Rao KP, Rao AS, Venugopal S. Materials science and engineering a 2007;456:11-19.

[23] Perepezko JH. Materials science and engineering a 2005;413-414:389-397.

[24] Li M, Ozawa S, Kuribayashi K. Philosophical magazine letters 2004;84:483-493.

[25] Porter DA, Easterling KE. Phase Transformations in Metals and Alloys. Chapman \& Hall, 1996.

[26] Barin I. Thermochemical Data of Pure Substances. VCH Publisher, 1995.

[27] Kurz W, Trivedi R. Materials science and engineering a 1994;179-180:4651.

[28] Liyanage T, Fisher G, Gerlich AP. Surface and coatings technology 2010;205:759-765.

[29] ASM Handbook, vol. 3. ASM International, n.d. 